\title{
The relationship between various measures of obesity and arterial stiffness in morbidly obese patients
}

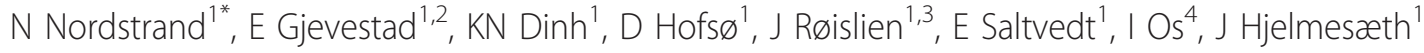

\begin{abstract}
Background: Obesity is associated with increased risk of cardiovascular disease. Arterial stiffness assessed by carotid femoral pulse wave velocity (PWV) is an independent predictor of cardiovascular morbidity and mortality. We aimed to investigate how various measures of body composition affect arterial stiffness.

Methods: This is an analysis of cross-sectional baseline data from a controlled clinical trial addressing changes in arterial stiffness after either surgery or lifestyle intervention in a population of morbidly obese patients. High-fidelity applanation tonometry (Millar ${ }^{\mathbb{B}}$, Sphygmocor ${ }^{\mathbb{B}}$ ) was used to measure pulse wave velocity (PW). Carotid femoral PWV is a direct measure of arterial stiffness and is considered to be the gold standard method. The Inbody 720 Body Composition Analyzer was used for bioelectrical impedance analysis (BIA). Spearman's correlation, independent samples $t$-test, chi-square tests, Fisher's exact test and multiple linear regression analyses were used as statistical methods.

Results: A total of 133 patients (79 women), with a mean (SD) age of 43 (11) years were included in the study. Men had a significantly higher prevalence of obesity related comorbidities and significantly higher PWV, 9.1 (2.0) $\mathrm{m} / \mathrm{s}$ vs. $8.1(1.8) \mathrm{m} / \mathrm{s}, \mathrm{p}=0.003$, than women. In the female group, PWV was positively correlated with WC, WHtR, $\mathrm{BMI}$ and visceral fat area. In the male group, PWV was negatively correlated with BMI. Multiple linear regression analysis showed that increasing BMI, WC, WHtR, visceral fat area and fat mass were independently associated with higher PWV in women, but not in men, after adjustment for age, hypertension and type 2 diabetes.
\end{abstract}

Conclusion: Most measures of general and abdominal obesity were predictors of arterial stiffness in female morbidly obese patients.

Trial registration: ClinicalTrials.gov Identifier NCT00626964

\section{Background}

The prevalence of obesity is rising globally, independent of ethnicity, race and age, and is associated with increased mortality and morbidity $[1,2]$. Obesity rates in Scandinavia represent no exception [3-5]. Importantly, the prevalence of morbid obesity, defined as BMI $\geq 40.0$ $\mathrm{kg} / \mathrm{m}^{2}$ or BMI $35.0-39.9 \mathrm{~kg} / \mathrm{m}^{2}$ and an obesity-related comorbidity, is increasing at an even steeper rate [6]. Two percent of the Norwegian population [7] can be classified as morbidly obese.

\footnotetext{
* Correspondence: njord.nordstrand@siv.no

${ }^{1}$ Morbid Obesity Centre, Vestfold Hospital Trust, Tønsberg, Norway

Full list of author information is available at the end of the article
}

Several lines of evidence indicate that the distribution of fat is a major determinant of cardiovascular risk in both normalweight, overweight and moderately obese subjects [8-10], although measures of general obesity and physiological differences between genders must also be considered [11-13]. Only a few studies in morbidly obese subjects have compared the effect of overall and central obesity on cardiovascular risks and the results have been inconsistent both within, and between genders [14-16]. Other studies have reported an increased risk of death in persons with BMI $>35 \mathrm{~kg} / \mathrm{m}^{2}[17,18]$, but the increase in mortality has been linked to comorbidities rather than the obesity [19] suggesting that

\section{Biomed Central}


morbid obesity without comorbidities is not a cardiovascular risk factor regardless of fat distribution.

Nevertheless, obesity is a major modifiable risk factor for coronary artery disease (CAD) that imparts a degree of cardiovascular risk similar to that associated with hypertension, hyperlipidemia, smoking and sedentary lifestyle [20]. Accordingly, it seems to be a paradox that the increasing obesity rates coincide with a decreased risk of cardiovascular death [21]. The latency time for developing cardiovascular disorders may, however, be several decades [22,23]. Thus, early risk markers are needed to identify obese subjects at risk.

Arterial stiffness assessed by pulse wave velocity (PWV) is an independent predictor of cardiovascular morbidity and mortality [24,25], and PWV is increasingly recognized as a valid surrogate endpoint of cardiovascular disease [26,27].

The main objective of this study was to examine the possible relationship between various measures of body composition and arterial stiffness PWV. We hypothesized that in morbidly obese subjects abdominal obesity is a better predictor of aortic stiffness than general obesity.

\section{Methods}

\section{Study design}

This is an analysis of cross-sectional baseline data from a non-randomized clinical trial comparing the effects of a comprehensive lifestyle modification program and bariatric surgery on arterial stiffness in morbidly obese patients. (http://ClinicalTrials.gov Identifier NCT00626964).

\section{Setting}

The study was performed at a tertiary care centre (the Morbid Obesity Centre, Vestfold Hospital Trust, Tønsberg, Norway) between February 2008 and January 2010. Before inclusion patients were either assigned to a comprehensive lifestyle modification program at the Hospital for Rehabilitation, Stavern, or to bariatric surgery at the Morbid Obesity Centre.

\section{Participants and study size}

All participants were recruited from our tertiary care centre and had to reside within $100 \mathrm{~km}$ of either the hospital for rehabilitation or our clinic. The patients in the intensive lifestyle intervention group were all selected from patients that had signed up for participation in a standardized health promoting and weight reductive program at the hospital for rehabilitation. Participants in the surgery group were selected from patients preparing for bariatric surgery at our hospital. The decision regarding the type of intervention was made prior to the inclusion to our study and was not a part of our protocol. Patients with one of the following conditions or diseases were excluded; uncompensated heart failure, cardiac arrhythmias, unstable angina, end-stage renal disease, known bleeding disturbances, serious psychiatric disorders, serious eating disorders, cardiac pacemakers, intra-cardiac devices, cerebrovascular event or a myocardial infarction within the last six months. The inclusion period started February 2008 and ended February 2010. Initially, 148 patients accepted our invitation to participate in the study, 15 patients withdrew their consent before the study started, leaving a total of 133 patients in the present analysis. The study was approved by the regional ethics committee of the Southern Norway Regional Health Authority, and was performed in accordance with the Declaration of Helsinki [28]. Written informed consent was provided by all participants.

\section{Variables}

The main outcome variable was arterial stiffness measured by PWV. The main explanatory variables were various measures and estimates of body composition, including anthropometric characteristics (WC, WHR, WHtR, BMI), data from bioelectrical impedance analysis (BIA) [visceral fat area $(\mathrm{cm} 2)$, fat mass $(\mathrm{kg})$ and fat free mass $(\mathrm{kg})]$. Potential confounders adjusted for were age, type 2 diabetes and arterial hypertension.

\section{Data sources and measurements}

All participants underwent a medical examination performed by a physician and a trained nurse. Blood was collected by venipuncture following an overnight fast on the day of medical examination. Weight and height were measured with patients wearing light clothing and no shoes. BMI was calculated as weight in kilograms divided by the square of the height in meters. WC $(\mathrm{cm})$ was measured midway between the 12th rib and the iliac crest. Blood pressure was measured after five minutes of rest using an electronic auscultatory blood pressure recorder with an appropriately sized cuff based on the measurement of arm circumference (Dinamap ${ }^{\circledR}$, ProCare Series, G.E. Medical Systems) with the patient sitting in the upright position. Three measurements were recorded, and the average of the second and third measurement was recorded and used in the analysis. Bioelectrical impedance measures were collected using the Inbody 720, Body Composition Analyzer, Biospace Co. Ltd. Arterial hypertension was defined by either, a systolic blood pressure $\geq 140 \mathrm{mmHg}$, diastolic blood pressure $\geq 90 \mathrm{mmHg}$ or the use of antihypertensive medication. Ischemic heart disease was defined as a history of stable coronary artery disease, percutaneous coronary intervention, coronary artery bypass graft surgery or myocardial infarction. The statistical analysis was performed using SPSS 16.0 (SPSS Inc., Chicago, IL). 


\section{Pulse wave velocity}

The measurement of PWV is generally accepted as the simplest, non-invasive, robust, and reproducible method to determine arterial stiffness and is considered to be the gold standard method [29-32]. ]. The Sphygmocor system (Artcor, Sidney, Australia) and a single high-fidelity applanation tonometer (Millar ${ }^{\circledR}$ ) were used to measure PWV. Pulse waves were obtained sequentially from the carotid and femoral artery. The PWV was calculated from the transit time and the distance between these two arterial sites, determined in relation to the $\mathrm{R}$-wave of the ECG, with patients lying in a horizontal position. Three complete sets of data were sampled and the average value was used as result. Bioelectrical impedance analysis was obtained using Inbody 720, Body Composition Analyzer, Biospace Co. Ltd. Each patient was undressed except for underwear, and placed in an upright position on the body composition analyzer. All jewelry and wristwatches were removed before the analyzer started recording. The InBody 720 uses the segmental BIA method in order to examine the body as five cylinders (four limbs and a trunk), and measures impedance in these parts separately. It also uses electrical current at multi-frequency (5, 50, 250, 500 and 1000 $\mathrm{kHz}$ ) in order to directly measure the amount of extracellular and intracellular water. Homeostasis Model Assessment Insulin Resistance (HOMA- IR) was calculated as ([fasting serum glucose $(\mathrm{mmol} / \mathrm{l}) \times$ fasting serum insulin (pmol/l)]/135 [33]. Low-density lipoprotein cholesterol (LDL) concentrations were estimated by the Friedewald equation: LDLcholesterol = Totalcholesterol - HDL-cholesterol - $(0.45 \times$ triglycerides $)$ [34]. S-LDL cholesterol was not calculated if S-triglycerides were $<0.2 \mathrm{mmol} / \mathrm{L}$ or $\geq 5 \mathrm{mmol} / \mathrm{L}$.

\section{Laboratory analyses}

Analyses of serum glucose and blood lipids were performed using dry reagent slide technology on the Vitros FS 5.1 (Ortho-Clinical Diagnostics, New York, USA). Glycated hemoglobin (HbA1c) was analyzed using high performance liquid chromatography on Tosoh HLC-723 G7 (Tosoh Corporation, Tokyo, Japan). Sera for analysis of insulin were stored at $-20^{\circ} \mathrm{C}$ and analyzed within one week of blood sampling (Linco Research Inc, St. Charles, MO). Immunoturbidimetric method was used for determinations of apolipoprotein A-1 and apolipoprotein B (Modular, Roche Diagnostic GmbH).

\section{Statistical methods}

Data are given as mean (SD) or $\mathrm{n}(\%)$. Skewed data were ln-transformed to approximate normality before statistical analyses (HOMA-IR, S-f-glucose, S-f-insulin and S-triglycerides). Spearman's rank correlation was used to assess the bivariate association between the outcome and each of the exposure variables. Gender differences were analyzed using independent samples $t$-test for continuous data, whilst Fisher's exact tests were used for categorical data. The multiple linear regression analyses included the various measures of body composition, age, hypertension and type 2 diabetes as independent variables, and aortic PWV as dependent variable. Significant interactions between gender and BMI ( $\mathrm{p}<0.001)$, WC $(\mathrm{p}=0.019)$ and WHtR $(\mathrm{p}<0.001)$ made it appropriate to perform gender specific linear regression analyses. Semi-partial (part) correlation coefficients were squared in order to calculate the percentage of total variance in the dependent variable explained by a given independent variable.

\section{Results}

A total of 133 morbidly obese persons (79 women), with a mean (SD) age of 43 (11) years, were included in the study. One hundred and six patients (59 women) had a BMI $\geq 40 \mathrm{~kg} / \mathrm{m}^{2}$. Thirty one patients ( 24 women) were morbidly obese based on BMI alone (no comorbidity and $\mathrm{BMI} \geq 40 \mathrm{~kg} / \mathrm{m}^{2}$ ), whilst 27 patients (18 women) had a BMI between 35 and $40 \mathrm{~kg} / \mathrm{m}^{2}$. Demographic characteristics, body composition and cardiovascular risk factors according to gender are shown in Table 1. The male patients had a significantly higher prevalence of hypertension, type 2 diabetes and ischemic heart disease, as well as higher levels of fasting insulin, glucose and HbA1c than the female patients. Conversely, men had lower levels of total cholesterol, LDL-cholesterol and HDL-cholesterol than women. The male patients had higher PWV than the female patients, [mean (SD) $9.1(2.0) \mathrm{m} / \mathrm{s}$ vs. $8.1(1.8) \mathrm{m} / \mathrm{s}, \mathrm{p}=0.003]$.

\section{Women}

In the female group, PWV was positively correlated with BMI, WC and WHtR (Figure 1). Table 2 shows that PWV was significantly correlated with visceral fat area, fasting glucose, HbA1c and the usage of $\beta$-blockers and calcium-channel blockers. Multiple linear regression analysis showed that BMI, WC, WHtR, visceral fat area and fat mass, but not WHR, were significantly associated with PWV after adjustment for age, hypertension and type 2 diabetes (table 3 ). Based on part correlation BMI explained $14 \%$ of the variation in PWV, with WHtR explaining $12 \%$, fat mass $8 \%$, visceral fat area $8 \%$ and WC 6\%.

\section{Men}

In the male group, PWV showed a significant negative correlation with BMI (Figure 1). The use of calciumchannel blockers, inhibitors of the RAA-system, statins and fasting glucose were positively correlated with PWV (Table 2). BMI showed a negative association with age, 
Table 1 Demographic characteristics, body composition, metabolic parameters and medications of 133 morbidly obese patients

\begin{tabular}{|c|c|c|c|c|}
\hline Variable & Total $(n=133)$ & Male $(n=54)$ & Female $(n=79)$ & $P$-value \\
\hline Age (years) & $43(11)$ & $45(11)$ & $41(10)$ & 0.107 \\
\hline Hypertension* (yes/no) & $90(68 \%)$ & $44(81 \%)$ & $46(58 \%)$ & 0.005 \\
\hline Type 2 diabetes (yes/no) & $38(29 \%)$ & $25(46 \%)$ & $13(17 \%)$ & $<0.001$ \\
\hline Ischemic heart disease (yes/no) & $7(5.3 \%)$ & $6(11.1 \%)$ & $1(1.3 \%)$ & 0.018 \\
\hline Current smoker (yes/no) & $20(15 \%)$ & $6(11 \%)$ & $14(18 \%)$ & 0.340 \\
\hline Weight (kg) & $132(22)$ & $146(23)$ & $121(16)$ & $<0.001$ \\
\hline \multicolumn{5}{|l|}{ Various measures of body composition } \\
\hline Waist-to-hip ratio & $0.99(0.10)$ & $1.17(0.07)$ & $0.94(0.07)$ & $<0.001$ \\
\hline Waist-to-height ratio & $75.3(6.4)$ & $79.2(6.2)$ & $74.4(5.9)$ & $<0.001$ \\
\hline Waist circumference $(\mathrm{cm})$ & $131(14)$ & $142(12)$ & $124(10)$ & $<0.001$ \\
\hline $\mathrm{BMI}\left(\mathrm{kg} / \mathrm{m}^{2}\right)$ & $44.5(5.6)$ & $46.1(6.3)$ & $43.5(4.8)$ & 0.008 \\
\hline Fat mass (kg) & $63(13)$ & $66(16)$ & $61(11)$ & 0.055 \\
\hline Fat free mass (kg) & $69(13)$ & $81(10)$ & $61(7)$ & $<0.001$ \\
\hline Visceral fat area $\left(\mathrm{cm}^{2}\right)$ & $242(48)$ & $262(55)$ & $228(37)$ & $<0.001$ \\
\hline \multicolumn{5}{|l|}{ Metabolic variables } \\
\hline apoB/apoA-1 ratio & $0.7(0.2)$ & $0.7(0.2)$ & $0.7(0.2)$ & 0.550 \\
\hline Fasting insulin (pmol/L) & $100(85)$ & $125(120)$ & $87(49)$ & 0.048 \\
\hline HOMA-IRT & $4.6(4.4)$ & $6.1(6.3)$ & $3.5(2.0)$ & 0.002 \\
\hline Fasting glucose $(\mathrm{mmol} / \mathrm{l})$ & $6.0(2.2)$ & $6.5(2.7)$ & $5.4(1.1)$ & 0.002 \\
\hline B-HbA1c (\%) & $6.2(1.3)$ & $6.5(1.6)$ & $5.7(0.7)$ & 0.001 \\
\hline Pulse pressure $(\mathrm{mmHg})$ & $62(16)$ & $63(15)$ & $61(17)$ & 0.471 \\
\hline \multicolumn{5}{|l|}{ Medication } \\
\hline$\beta$-blocker (yes/no) & $13(10 \%)$ & $8(15 \%)$ & $5(6 \%)$ & 0.134 \\
\hline Calsium-channel blocker (yes/no) & $17(13 \%)$ & $10(19 \%)$ & $7(9 \%)$ & 0.125 \\
\hline Inhibitors of the RAA-system (yes/no) & $37(28 \%)$ & $23(43 \%)$ & $14(18 \%)$ & 0.003 \\
\hline Statins (yes/no) & $18(14 \%)$ & $13(24 \%)$ & $5(6 \%)$ & 0.008 \\
\hline
\end{tabular}

Data are given as number (\%) or mean (SD). *Hypertension is defined by the patient receiving antihypertensive medication or having systolic blood pressure $\geq$ $140 \mathrm{mmHg}$ or diastolic blood pressure $\geq 90 \mathrm{mmHg}$. † Homeostasis Model Assessment Insulin Resistance.

$\mathrm{r}=-0.449, \mathrm{p}=0.001$. Multiple linear regression analysis (Table 3) did not demonstrate any significant association between measures of body composition and PWV after adjustment for age, hypertension and type 2 diabetes.

\section{Discussion}

\section{Key results}

Our results indicate that measures of both general obesity and abdominal obesity are associated with PWV in morbidly obese women, but not in men. Thus, we could not confirm our initial hypothesis that abdominal obesity was a better predictor of aortic stiffness than general obesity.

\section{Comparison with previous studies}

Our results support the findings of a previous study of normal weight and less obese European Caucasians which demonstrated that PWV increased with higher BMI in middle-aged and older women, but not in men [35]. Further, we are able to extend these findings to be valid in morbidly obese women. Partly in contrast with our findings, WC, but not BMI, was significantly associated with PWV in a cross-sectional study of middle aged, apparently healthy subjects [36]. In addition, no significant correlation between BMI and PWV was revealed in a recent prospective study of 29 morbidly obese subjects [37]. These discrepancies might have several explanations, including the low percentage of obese participants in the former study and the low number of participants in the latter. On the other hand, a study of less obese African-Americans and whites demonstrated that increased BMI, WC, and WHR were associated with higher PWV in both men and women [38]. Finally, baseline data from a longitudinal study of 50 (12 men) healthy obese patients (BMI > $30 \mathrm{~kg} / \mathrm{m} 2)$ [39] showed that BMI and total fat mass, but not visceral fat mass, assessed by magnetic resonance imaging, were significantly associated with PWV in both genders. The latter is in opposition to our finding of a significant association between visceral fat area assessed by BIA and PWV in women. This difference in results might partly be explained by the higher degree of obesity in our study population and the larger proportion of metabolic disorders. 

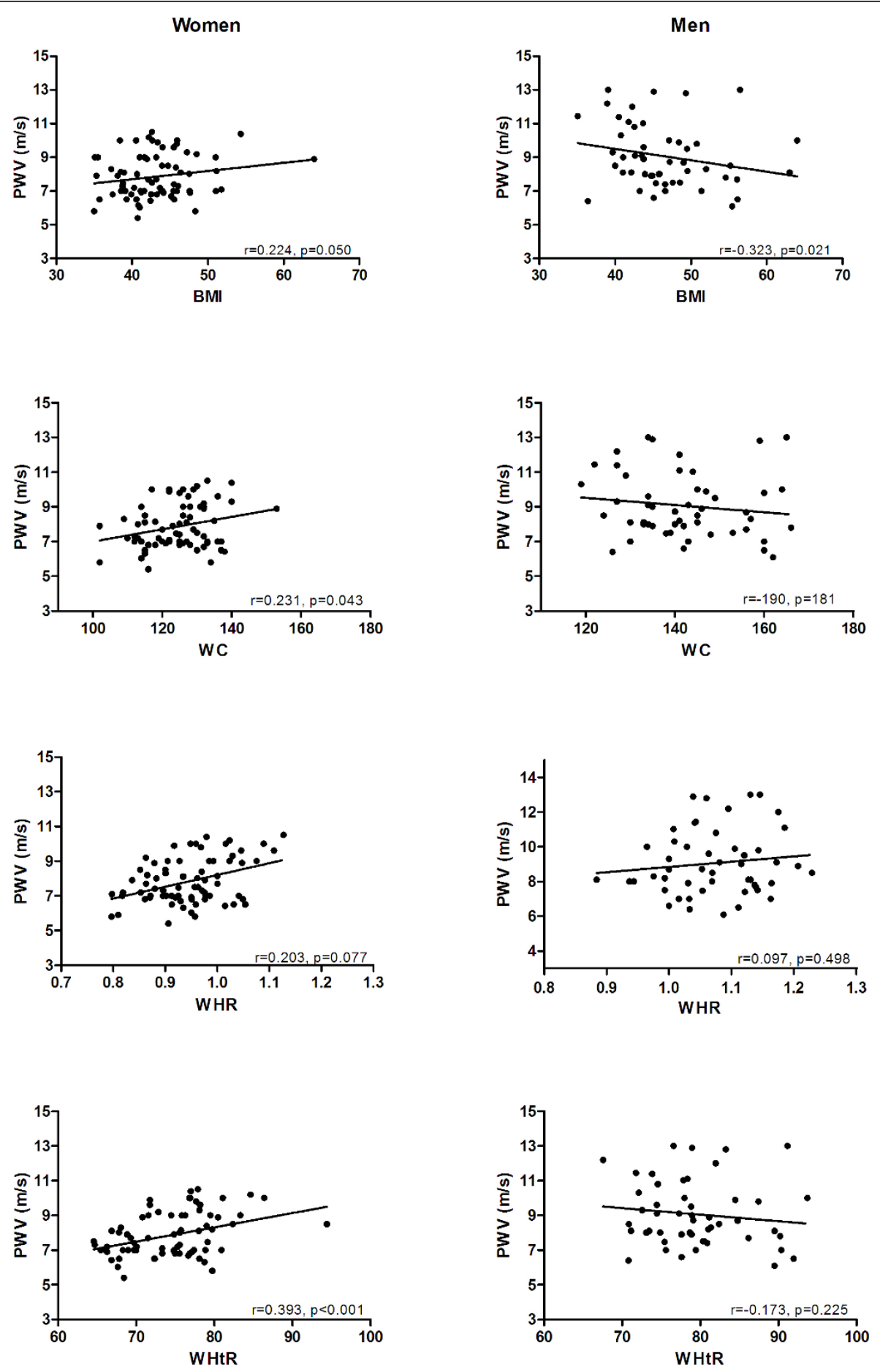

Figure 1 Correlations between anthropometric measures and PWV. The scatterplots show the relationship between anthropometric measures and PWV.

\section{Gender differences}

It is well known that for any given BMI, men have a larger amount of visceral adipose tissue and a higher risk of cardiovascular disease than women [13]. Our results are in agreement with this. Accordingly, our findings are discussed separately in men and women [40]. In the present study we observed an apparent lack of association between obesity and PWV among male patients in the multivariate analysis (Table 3 ). This might partly be explained by a significantly higher prevalence of 
Table 2 Correlations between PWV, body composition, metabolic parameters and medications

\begin{tabular}{lcc}
\hline Independent variables & Male $(\mathbf{r})$ & Female $(\mathbf{r})$ \\
\hline Age & $0.61 \dagger$ & $0.52 \dagger$ \\
Hypertension $\neq$ & 0.19 & $0.59 \dagger$ \\
Type 2 diabetes (yes/no) & $0.46 \dagger$ & 0.18 \\
Visceral fat area $\left(\mathrm{cm}^{2}\right)$ & -0.18 & $0.25^{*}$ \\
Fat mass (kg) & -0.26 & 0.06 \\
Fat free mass (kg) & -0.15 & -0.04 \\
apo-B/apoA-1 ratio & -0.29 & 0.10 \\
Fasting insulin (mmol/L) & 0.03 & 0.09 \\
HOMA IR§ & 0.10 & 0.13 \\
Fasting glucose (mmol/L) & $0.35^{*}$ & $0.24^{*}$ \\
HbA1c (\%) & 0.27 & $0.31^{*}$ \\
$\beta$-blocker (yes/no) & 0.12 & $0.39 \dagger$ \\
Calsium-channel blocker (yes/no) & $0.36^{*}$ & $0.24^{*}$ \\
Inhibitors of the RAA-system (yes/no) & $0.29^{*}$ & 0.14 \\
Statins (yes/no) & $0.39^{*}$ & 0.22 \\
\hline
\end{tabular}

${ }^{*} \mathrm{p}<0.05 . \mathrm{tp}<0.001$. $\neq$ Hypertension is defined by the patient receiving antihypertensive medication or having systolic bloodpressure $\geq 140 \mathrm{mmHg}$ or diastoic blood pressure $\geq 90 \mathrm{mmHg}$. §Homeostasis Model Assessment Insulin Resistance.

comorbidities and conditions known to increase PWV; such as hypertension, type 2 diabetes, ischemic heart disease and insulin resistance in our male population. Conversely, a weak negative correlation between BMI and PWV was shown in the univariate analysis of male subjects (Figure 1). This surprising finding might partly be explained by the coexistence of a significant negative correlation between age and BMI and the moderate positive correlation between age and PWV in our study. Finally, we cannot exclude the possibility that the

Table 3 Independent predictors of PWV after adjustment for age, hypertension and type 2 diabetes.

\begin{tabular}{|c|c|c|c|c|}
\hline Body composition & B & $95 \% \mathrm{Cl}$ & $\mathbf{P}$ & R Square \\
\hline \multicolumn{5}{|l|}{ Female } \\
\hline Body mass index $\left(\mathrm{kg} / \mathrm{m}^{2}\right)$ & 0.129 & 0.068 to 0.190 & $<0.001$ & 0.42 \\
\hline Waist circumference $(\mathrm{cm})$ & 0.047 & 0.010 to 0.083 & 0.013 & 0.33 \\
\hline Waist-to-hip ratio & -1.297 & -6.109 to 3.522 & 0.594 & 0.28 \\
\hline Waist-to-height ratio & 0.108 & 0.052 to 0.164 & $<0.001$ & 0.40 \\
\hline Visceral fat area $\left(\mathrm{cm}^{2}\right)$ & 0.014 & 0.005 to 0.024 & 0.004 & 0.35 \\
\hline Fat mass (kg) & 0.047 & 0.015 to 0.080 & 0.004 & 0.35 \\
\hline Fat free mass $(\mathrm{kg})$ & 0.009 & -0.046 to 0.065 & 0.736 & 0.27 \\
\hline \multicolumn{5}{|l|}{ Male } \\
\hline Body mass index $\left(\mathrm{kg} / \mathrm{m}^{2}\right)$ & -0.009 & -0.083 to 0.065 & 0.806 & 0.47 \\
\hline Waist circumference $(\mathrm{cm})$ & 0.014 & -0.023 to 0.052 & 0.440 & 0.48 \\
\hline Waist-to-hip ratio & 1.933 & -3.707 to 7.574 & 0.494 & 0.48 \\
\hline Waist-to-height ratio & 0.021 & -0.053 to 0.094 & 0.575 & 0.48 \\
\hline Visceral fat area $\left(\mathrm{cm}^{2}\right)$ & 0.003 & -0.005 to 0.011 & 0.470 & 0.49 \\
\hline Fat mass (kg) & 0.005 & -0.024 to 0.035 & 0.719 & 0.48 \\
\hline Fat free mass $(\mathrm{kg})$ & 0.008 & -0.033 to 0.050 & 0.693 & 0.48 \\
\hline
\end{tabular}

Multiple linear regression analysis. number of male patients was too low to reveal a possible association between obesity and PWV.

\section{Body Composition}

The associations between various measures of overall and abdominal obesity and PWV in women were comparable in the present study. However, the amount of fat tissue associated with morbid obesity is likely to cause an accumulation of both visceral and subcutaneous fat. The effect of this can be a loss of superiority of one anthropometric measure of obesity to the other. Another area of concern is the relatively low reliability of the different anthropometric measures in this population[41]. This could imply that the correlations are underestimated and thus should be interpreted with caution. In addition, and in accordance with previous studies [9,42], the anthropometric indexes taking height into account (BMI and WHtR) seemed to explain a larger part of the variation in PWV than WC, visceral fat area and fat mass. Accordingly, the usage of WC may underestimate the relative amount of abdominal fat in short subjects and overestimate it in tall subjects and consequently be misleading.

It is difficult to explain the lack of association between WHR and PWV in our study. This finding is in opposition to several other studies designed to explore the predictive value of various measures of obesity in relation to cardiovascular risk factors [43]. The detrimental effects of abdominal obesity may mitigate against the possible protective effect of subcutaneous fat located at the hip, despite only slightly increased WHR in morbidly obese patients. The low reliability of WHR as compared with WC in a morbidly obese population is also a factor that should be considered [41].

\section{Other factors related to arterial stiffness}

In accordance with a recent study [44] demonstrating a significant association between fasting glucose and PWV in middle aged overweight and obese subjects, we found a significant positive correlation between fasting glucose and PWV in both men and women. In women, but not in men, we also found a positive correlation between $\mathrm{HbA1c}$ and PWV. Conversely, we could not demonstrate any association between HOMA-IR and PWV as shown in the previous study [44]. An elevated glucose level can cause a non-enzymatic glycation of matrix proteins and result in the accumulation of glycation end-products within the arterial wall and subsequent arterial stiffness [45].

\section{Limitations and strengths}

The major strengths of the present study are that arterial stiffness is a well validated risk marker of cardiovascular morbidity and mortality, as well as that PWV is considered to be the "gold standard" in assessing arterial 
stiffness. In terms of weaknesses, the cross-sectional design of the study necessarily implies that we cannot establish a cause-effect relationship. All but one participant, were white, and we are thus unable to generalize our results to non-white populations. It should also be noted that BIA is not considered to be a "gold standard" method. BIA has a tendency to underestimate the amount of fat tissue in morbidly obese patients when compared to hydrostatic weighing and dual-energy Xray absorptiometry [46-48], although this is minimized by the usage of the segmental BIA method and multifrequency technology in the present study.

\section{Conclusion}

Most measures of general and abdominal obesity were associated with arterial stiffness in morbidly obese women.

\section{Acknowledgements}

We thank the following employees at the Morbid Obesity Center at Vestfold Hospital Trust: Heidi Omre Fon, Berit Mossing Bjørkås and Linda Mathisen for their assistance with sampling and logistics, and Matthew McGee for proofreading the manuscript. We also would like to thank the employees at the Department of Medical Biochemistry, Oslo University Hospital, Rikshospitalet for their assistance in the analysis of Apolipoprotein A-1 and Apolipoprotein B.

\section{Author details}

${ }^{1}$ Morbid Obesity Centre, Vestfold Hospital Trust, Tønsberg, Norway. ${ }^{2}$ Hospital for Rehabilitation, Department of Physical Medicine, Stavern, Norway. ${ }^{3}$ Oslo University Hospital, Department of Biostatistics, Institute of Basic Medical Sciences, Rikshospitalet, Norway. ${ }^{4}$ Oslo University Hospital, Department of Nephrology and Hypertension, Ullevål, Norway.

\section{Authors' contributions}

$\mathrm{NN}$ and $\mathrm{JH}$ : contributed to the study design and organized the study; NN analyzed the data and wrote the manuscript; NN, EG and KN: performed the technical analysis of arterial stiffness and were involved in drafting the manuscript and revised it critically for important intellectual content. JR: reviewed the statistical analyses and revised the manuscript critically for important intellectual content; $\mathrm{JH}, \mathrm{DH}, \mathrm{IO}$, and ES: contributed to

interpretation of data, were involved in drafting the manuscript and revised it critically for important intellectual content. All authors read and approved the final manuscript

\section{Competing interests}

The authors declare that they have no competing interests.

Received: 25 June 2010 Accepted: 1 February 2011

Published: 1 February 2011

\section{References}

1. Lobstein $T$, Jackson-Leach R: Child overweight and obesity in the USA: prevalence rates according to IOTF definitions. International Journal of Pediatric Obesity 2007, 2:62-64.

2. Prentice AM: The emerging epidemic of obesity in developing countries. [Review] [54 refs]. International Journal of Epidemiology 2006, 35:93-99.

3. Droyvold WB, Nilsen TI, Kruger O, Holmen TL, Krokstad S, Midthjell K, et al: Change in height, weight and body mass index: Longitudinal data from the HUNT Study in Norway. International Journal of Obesity 2006 30:935-939.

4. Neovius M, Janson A, Rossner S: Prevalence of obesity in Sweden. [Review] [15 refs]. Obesity Reviews 2006, 7:1-3.
5. Bendixen H, Holst C, Sorensen TI, Raben A, Bartels EM, Astrup A: Major increase in prevalence of overweight and obesity between 1987 and 2001 among Danish adults. Obesity Research 2004, 12:1464-1472.

6. Sturm R: Increases in morbid obesity in the USA: 2000-2005. Public Health 2007, 121:492-496.

7. Graff-Iversen S, Jenum AK, Grøtvedt L, Bakken B, Selmer RM, Søgard AJ: Risikofaktorer for hjerteinfarkt, hjerneslag og diabetes i Norge. Tidsskrift for Den Norske Laegeforening 2007, 127:2537-2541.

8. Larsson B, Svardsudd K, Welin L, Wilhelmsen L, Bjorntorp P, Tibblin G: Abdominal adipose tissue distribution, obesity, and risk of cardiovascular disease and death: 13 year follow up of participants in the study of men born in 1913. British Medical Journal Clinical Research Ed 1984, 288:1401-1404

9. Schneider HJ, Friedrich N, Klotsche J, Pieper L, Nauck M, John U, et al: The predictive value of different measures of obesity for incident cardiovascular events and mortality. Journal of Clinical Endocrinology \& Metabolism 2010, 95:1777-1785.

10. Yusuf S, Hawken S, Ounpuu S, Bautista L, Franzosi MG, Commerford P, et al: Obesity and the risk of myocardial infarction in 27,000 participants from 52 countries: a case-control study. Lancet 2005, 366:1640-1649.

11. van D, Kromhout D, Geleijnse JM, Boer JM, Verschuren WM: Body mass index and waist circumference predict both 10-year nonfatal and fatal cardiovascular disease risk: study conducted in 20,000 Dutch men and women aged 20-65 years. European Journal of Cardiovascular Prevention \& Rehabilitation 2009, 16:729-734

12. Wang W, Zhao D, Sun JY, Liu J, Liu J, Qin LP, et al: [Predictive value of combined measurements of body mass index and waist circumference for the risk of cardiovascular disease]. [Chinese]. Chung-Hua Hsin Hsueh Kuan Ping Tsa Chih [Chinese Journal of Cardiology] 2008, 36:655-658.

13. Geer EB, Shen W: Gender differences in insulin resistance, body composition, and energy balance. [Review] [156 refs]. Gender Medicine 2009, 6(Suppl):75.

14. Drapeau V, Lemieux I, Richard D, Bergeron J, Tremblay A, Biron S, et al: Waist circumference is useless to assess the prevalence of metabolic abnormalities in severely obese women. Obesity Surgery 2007, 17:905-909.

15. Lemieux I, Drapeau V, Richard D, Bergeron J, Marceau P, Biron S, et al: Waist girth does not predict metabolic complications in severely obese men. Diabetes Care 2006, 29:1417-1419.

16. Ledoux S, Coupaye M, Essig M, Msika S, Roy C, Queguiner I, et al: Traditional anthropometric parameters still predict metabolic disorders in women with severe obesity. Obesity 2010, 18:1026-1032.

17. Engeland A, Bjorge T, Selmer RM, Tverdal A: Height and body mass index in relation to total mortality. Epidemiology 2003, 14:293-299.

18. Sjostrom LV: Mortality of severely obese subjects. American Journal of Clinical Nutrition 1992, 55(Suppl):523S.

19. Livingston $\mathrm{EH}, \mathrm{Ko} \mathrm{CY}$ : Effect of diabetes and hypertension on obesityrelated mortality. Surgery 2005, 137:16-25.

20. Melanson KJ, McInnis KJ, Rippe JM, Blackburn G, Wilson PF: Obesity and cardiovascular disease risk: research update. [Review] [50 refs]. Cardiology in Review 2001, 9:202-207.

21. Claudi T, Midthjell $K$, Holmen J, Fougner $K$, Kruger O, Wiseth R: Cardiovascular disease and risk factors in persons with type 2 diabetes diagnosed in a large population screening: the Nord-Trondelag Diabetes Study, Norway. Journal of Internal Medicine 2000, 248:492-500.

22. Cassidy AE, Bielak LF, Zhou Y, Sheedy PF, Turner ST, Breen JF, et al: Progression of subclinical coronary atherosclerosis: does obesity make a difference? Circulation 2005, 111:1877-1882

23. Lakka TA, Lakka HM, Salonen R, Kaplan GA, Salonen JT: Abdominal obesity is associated with accelerated progression of carotid atherosclerosis in men. Atherosclerosis 2001, 154:497-504.

24. Laurent S, Boutouyrie P, Asmar R, Gautier I, Laloux B, Guize L, et al: Aortic stiffness is an independent predictor of all-cause and cardiovascular mortality in hypertensive patients. Hypertension 2001, 37:1236-1241.

25. Laurent S, Katsahian S, Fassot C, Tropeano Al, Gautier I, Laloux B, et al: Aortic stiffness is an independent predictor of fatal stroke in essential hypertension. Stroke 2003, 34:1203-1206.

26. Vlachopoulos C, Aznaouridis K, Stefanadis C: Prediction of cardiovascular events and all-cause mortality with arterial stiffness: a systematic review and meta-analysis. [Review] [49 refs]. Journal of the American College of Cardiology 2010, 55:1318-1327. 
27. Lim HE, Park CG, Shin SH, Ahn JC, Seo HS, Oh DJ: Aortic pulse wave velocity as an independent marker of coronary artery disease. Blood Pressure 2004, 13:369-375.

28. World Medical Association declaration of Helsinki. Recommendations guiding physicians in biomedical research involving human subjects. JAMA 1997, 277:925-926.

29. Laurent S, Cockcroft J, Van BL, Boutouyrie P, Giannattasio C, Hayoz D, et al: Expert consensus document on arterial stiffness: methodological issues and clinical applications. European Heart Journal 2006, 27:2588-2605.

30. Laurent S, Boutouyrie P: Arterial stiffness: a new surrogate end point for cardiovascular disease?. [Review] [29 refs]. Journal of Nephrology 2007, 20(Suppl):50.

31. Mansia G, De BG, Dominiczak A, Cifkova R, Fagard R, Germano G, et al: 2007 ESH-ESC Guidelines for the management of arterial hypertension: the task force for the management of arterial hypertension of the European Society of Hypertension (ESH) and of the European Society of Cardiology (ESC). Blood Pressure 2007, 16:135-232.

32. Willum-Hansen T, Staessen JA, Torp-Pedersen C, Rasmussen S, Thijs L, Ibsen $\mathrm{H}$, et al: Prognostic value of aortic pulse wave velocity as index of arterial stiffness in the general population. Circulation 2006, 113:664-670.

33. Matthews DR, Hosker JP, Rudenski AS, Naylor BA, Treacher DF, Turner RC: Homeostasis model assessment: insulin resistance and beta-cell function from fasting plasma glucose and insulin concentrations in man. Diabetologia 1985, 28:412-419.

34. Friedewald WT, Levy RI, Fredrickson DS: Estimation of the concentration of low-density lipoprotein cholesterol in plasma, without use of the preparative ultracentrifuge. Clinical Chemistry 1972, 18:499-502.

35. Zebekakis PE, Nawrot T, Thijs L, Balkestein EJ, Heijden-Spek J, Van Bortel LM, et al: Obesity is associated with increased arterial stiffness from adolescence until old age. Journal of Hypertension 2005, 23:1839-1846.

36. Czernichow S, Bertrais S, Oppert JM, Galan P, Blacher J, Ducimetiere P, et al: Body composition and fat repartition in relation to structure and function of large arteries in middle-aged adults (the SU.VI.MAX study). International Journal of Obesity 2005, 29:826-832.

37. Faintuch J, Marques PC, Bortolotto LA, Faintuch JJ, Cecconello I: Systemic inflammation and cardiovascular risk factors: are morbidly obese subjects different? Obesity Surgery 2008, 18:854-862.

38. Wildman RP, Mackey RH, Bostom A, Thompson T, Sutton-Tyrrell K: Measures of obesity are associated with vascular stiffness in young and older adults. Hypertension 2003, 42:468-473.

39. Rider OJ, Tayal U, Francis JM, Ali MK, Robinson MR, Byrne JP, et al: The effect of obesity and weight loss on aortic pulse wave velocity as assessed by magnetic resonance imaging. Obesity 2010, 18:2311-2316.

40. Anand SS, Islam S, Rosengren A, Franzosi MG, Steyn K, Yusufali AH, et al: Risk factors for myocardial infarction in women and men: insights from the INTERHEART study. European Heart Journal 2008, 29:932-940.

41. Nordhamn K, Sodergren E, Olsson E, Karlstrom B, Vessby B, Berglund L: Reliability of anthropometric measurements in overweight and lean subjects: consequences for correlations between anthropometric and other variables. International Journal of Obesity \& Related Metabolic Disorders: Journal of the International Association for the Study of Obesity 2000, 24:652-657.

42. Lee CM, Huxley RR, Wildman RP, Woodward M: Indices of abdominal obesity are better discriminators of cardiovascular risk factors than BMI: a meta-analysis. [Review] [29 refs]. Journal of Clinical Epidemiology 2008, 61:646-653.

43. Huxley R, Mendis S, Zheleznyakov E, Reddy S, Chan J: Body mass index, waist circumference and waist:hip ratio as predictors of cardiovascular risk-a review of the literature. [Review] [23 refs]. European Journal of Clinical Nutrition 2010, 64:16-22

44. Webb DR, Khunti K, Silverman R, Gray LJ, Srinivasan B, Lacy PS, et al: Impact of metabolic indices on central artery stiffness: independent association of insulin resistance and glucose with aortic pulse wave velocity. Diabetologia 2010, 53:1190-1198.

45. Aronson D: Cross-linking of glycated collagen in the pathogenesis of arterial and myocardial stiffening of aging and diabetes. [Review] [81 refs]. Journal of Hypertension 2003, 21:3-12.

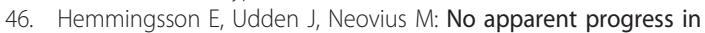
bioelectrical impedance accuracy: validation against metabolic risk and DXA. Obesity 2009, 17:183-187.
47. Volgyi E, Tylavsky FA, Lyytikainen A, Suominen H, Alen M, Cheng S: Assessing body composition with DXA and bioimpedance: effects of obesity, physical activity, and age. Obesity 2008, 16:700-705.

48. Heath EM, Adams TD, Daines MM, Hunt SC: Bioelectric impedance and hydrostatic weighing with and without head submersion in persons who are morbidly obese. Journal of the American Dietetic Association 1998, 98:869-875.

\section{Pre-publication history}

The pre-publication history for this paper can be accessed here: http://www.biomedcentral.com/1471-2261/11/7/prepub

doi:10.1186/1471-2261-11-7

Cite this article as: Nordstrand et al:: The relationship between various measures of obesity and arterial stiffness in morbidly obese patients. BMC Cardiovascular Disorders 2011 11:7.

\section{Submit your next manuscript to BioMed Central and take full advantage of:}

- Convenient online submission

- Thorough peer review

- No space constraints or color figure charges

- Immediate publication on acceptance

- Inclusion in PubMed, CAS, Scopus and Google Scholar

- Research which is freely available for redistribution

Submit your manuscript at www.biomedcentral.com/submit
C) Biomed Central 